\title{
Impact of Maternal Age on Oocyte and Embryo Competence
}

\author{
Danilo Cimadomo ${ }^{1 *}$, Gemma Fabozzi ${ }^{1}$, Alberto Vaiarelli ${ }^{1}$, Nicolò Ubaldi ${ }^{2}$, \\ Filippo Maria Ubaldi' and Laura Rienzi ${ }^{1}$ \\ ${ }^{1}$ Clinica Valle Giulia, G.en.e.r.a. Centers for Reproductive Medicine, Rome, Italy, ${ }^{2}$ Catholic University of \\ the Sacred Heart, Rome, Italy
}

The overall success of human reproduction, either spontaneously or after IVF, is highly dependent upon maternal age. The main reasons for age-related infertility include reduced ovarian reserve and decreased oocyte/embryo competence due to aging insults, especially concerning an increased incidence of aneuploidies and possibly decreased

OPEN ACCESS

Edited by:

Sandro C. Esteves,

Androfert, Andrology and

Human Reproduction

Clinic, Brazil

Reviewed by:

Hakan Yarali,

Anatolia IVF, Turkey

Jung Ryeol Lee,

Seoul National University

College of Medicine,

South Korea

Matheus Roque,

ORIGEN - Center for

Reproductive Medicine, Brazil

*Correspondence:

Danilo Cimadomo

cimadomo@generaroma.it

Specialty section:

This article was submitted

to Reproduction,

a section of the journal

Frontiers in Endocrinology

Received: 03 April 2018

Accepted: 31 May 2018

Published: 29 June 2018

Citation:

Cimadomo D, Fabozzi G, Vaiarelli A, Ubaldi N, Ubaldi FM and Rienzi L (2018) Impact of Maternal Age on Oocyte and Embryo Competence.

Front. Endocrinol. 9:327. doi: 10.3389/fendo.2018.00327 mitochondrial activity. Age-related chromosomal abnormalities mainly arise because of meiotic impairments during oogenesis, following flawed chromosome segregation patterns such as non-disjunction, premature separation of sister chromatids, or the recent reverse segregation. In this review, we briefly discuss the main mechanisms putatively impaired by aging in the oocytes and the deriving embryos. We also report the main strategies proposed to improve the management of advanced maternal age women in IVF: fertility preservation through oocyte cryopreservation to prevent aging; optimization of the ovarian stimulation and enhancement of embryo selection to limit its effects; and oocyte donation to circumvent its consequences.

Keywords: ovarian reserve, oocyte competence, aging, aneuploidies, IVF

\section{INTRODUCTION}

Human reproduction success is highly dependent upon the age at which women attempt to conceive, which is progressively increasing worldwide $(1,2)$. Fertility decreases as the woman ages, while the incidence of miscarriage and the prevalence of vital chromosomal abnormalities follow an opposite trend (2-4) (Figure 1). In IVF, maternal age is among the strongest predictors of success (5). Specifically, advanced maternal age (AMA; defined as $\geq 35$ years) shows just a negligible impact upon fertilization rate $(6,7)$ and a mild impact upon embryo development to the blastocyst stage $(8,9)$, but results in a dramatic impact upon blastocyst aneuploidy rate $(10,11)$ (Figure 1). However, the molecular and biochemical mechanisms involved in age-related infertility and their impact on oocyte and embryo quality remain to be clearly elucidated. Up to date, several dysfunctions have been associated with impaired fertility in aged women. Together with a progressive reduction of the ovarian reserve, woman aging involves also a compromised competence of the oocytes/embryos because of defective physiological pathways, such as energy production and balance, metabolism, epigenetic regulation, cell cycle checkpoints, and increased meiotic missegregation $(11,12)$. In this review, we provide a summary of the main putative causes for the age-related decrease in oocyte/embryo competence, along with the mechanisms underlying aging and the main clinical strategies proposed to prevent/limit the impact of AMA upon IVF success. 


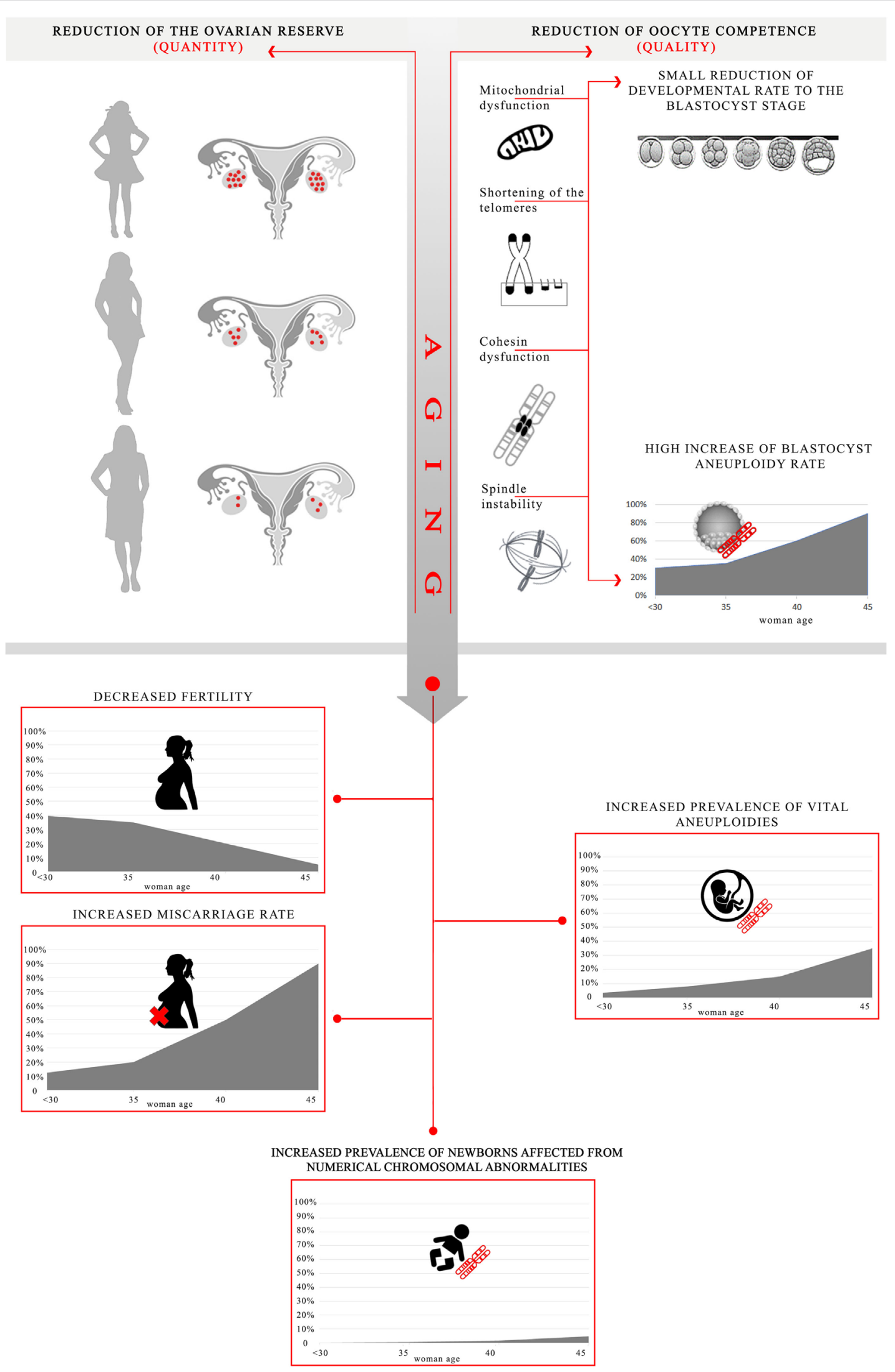

FIGURE 1 | Continued 
FIGURE 1 | Effect of advanced maternal age on oocyte/embryo competence and putative mechanisms impaired by aging. Aging in women causes both a reduction of the ovarian reserve and of the oocyte competence. All the processes impaired may result into a lower energy production/balance involving a small reduction of embryo developmental rate to the blastocyst stage, as well as a higher frequency of chromosome missegregation during maternal meiosis leading to a high increase in blastocyst aneuploidy rate (especially in women older than 35) [data adapted from Franasiak et al. (10) and Capalbo et al. (11)]. Ultimately, these mechanisms converge into a decreased fertility, an increased prevalence of vital chromosomal abnormalities, an increased miscarriage rate, as well as an increased prevalence of numerical chromosomal abnormalities in the newborns [data adapted from Hassold and Hunt (13) and Heffner (4)]. The aneuploidy rate is estimated per biopsied blastocyst; the fertility is estimated as number of babies born per 1,000 married women; the overall prevalence of vital aneuploidies is estimated per clinically recognized pregnancy; the miscarriage rate is estimated per clinical pregnancy; at last, the overall prevalence of numerical chromosomal abnormalities is estimated per number of newborns.

\section{MATERNAL AGING AND ANEUPLOIDIES}

The oocyte must sustain embryo development until embryonic genome activation (EGA) (14). To effectively reach EGA, synchronous nuclear and cytoplasmic maturation are required. Any failure in these processes may cause an incorrect transition from a maternal to an embryonic control upon embryo development. However, after birth and until follicle recruitment and ovulation, the oocytes enter a protracted arrest in the prophase of meiosis I, during which they are subject to the detrimental effects of aging, especially impairing the genetic stability (15), and ultimately affecting the chance of success in human reproduction. Indeed, the oocytes hold most of the reproductive potential in humans, as demonstrated by the restored fertility in women who undergo egg donation (16).

Maternal age is the main cause of embryonic aneuploidies $(4,13,17)$. More than $90 \%$ of these imbalances are indeed of maternal origin caused by chromosomal missegregation during oogenesis (15). Mainly meiosis I errors may occur (>70\% of cases), which although can be "corrected" in meiosis II, thereby resolving the initial error (11).

If full-chromosome constitutive aneuploidies are mainly generated by a defective maternal meiosis, structural chromosomal abnormalities (e.g., balanced translocations) seem instead independent from maternal age and may equally affect both the partners together with segmental aneuploidies, copy number variations, microdeletions/microduplications, and post-zygotic mitotic errors. Indeed, they probably arise from de novo events during either oogenesis and spermatogenesis or mitosis $(18,19)$.

The maintenance of the bivalent structure is a critical issue in maternal meiosis. In humans, homologous chromosomes recombine in primary oocytes during fetal development to form a bivalent configuration at meiotic prophase I. This configuration must be maintained for years, along which the oocytes remain arrested at the G2/M transition (dictyate stage) until menarche. At this stage, meiosis resumption and chromosome segregation take place. However, during this extended period of quiescence, the bivalent structure may weaken, leading to the formation of univalents or to sister chromatids splitting at meiosis I. The incidence of both these events indeed correlates with increased maternal age and reduced recombination rate (20-25), but the related causative mechanisms are still unclear. Two hypotheses have been proposed: (i) the univalents originate from bivalents deterioration throughout the dictyate arrest or (ii) the oocytes that underwent deficient recombination are ovulated last from the ovary.
Surprisingly, Ottolini and colleagues recently reported, via the karyomapping technique (a method that through the specific parental haplotypes allows the definition of an SNPs-based map of each chromatid) applied to artificially activated human oocytes and their polar bodies, that the most common non-canonical segregation pattern is reverse segregation (26). According to this novel segregation scheme, which cannot be identified by conventional copy number analysis, the non-sister chromatids, instead of the homologous, segregate together in meiosis I. This pattern, even if unconventional, does not result in an unbalanced chromosomal constitution per se, unless it is followed by a further error during meiosis II. Therefore, the most common segregation error of maternal meiosis reported in the majority of activated/fertilized oocytes is still the premature separation of sister chromatids (PSSC) in meiosis I (27-30). At last, meiosis I or meiosis II non-disjunction events should be accounted as causes of maternal meiotic impairments, even though probably less frequent than what previously reported $(31,32)$.

Hereafter, we summarize the molecular and cellular processes that may be affected because of aging in the oocytes $(33,34)$ : mitochondrial dysfunction, shortening of telomeres, cohesins dysfunction, and meiotic spindle abnormalities due to spindleassembly checkpoint (SAC) impairment. Reduced development to the blastocyst stage and/or chromosomal abnormalities are their putative consequences (Figure 1).

\section{PUTATIVE MECHANISMS IMPAIRED BY AGING AND LEADING TO A REDUCED OOCYTE/EMBRYO COMPETENCE}

\section{Mitochondrial Dysfunction}

Mitochondria are the most numerous organelles in the oocyte and represent its powerhouse. They are characterized by their own genome (mtDNA) and constitute the main maternal contribution to embryogenesis (35). Indeed, the sperm does not provide mitochondria to the offspring. They are considered pivotal especially in the delicate first phases of preimplantation development, when a balanced energy consumption is crucial for an efficient oocyte cytoplasmic and nuclear maturation, throughout processes such as germinal vesicle breakdown, or microtubule assembly and disassembly during meiotic spindle formation $(36,37)$. Moreover, mitochondria cover an essential role in various signaling pathways, such as $\mathrm{Ca}^{2+}$ signaling and regulation of the intracellular red-ox potential, particularly important for fertilization and early development $(36,38)$. 
The adverse effect of aging upon the mitochondria within the oocyte has been widely reported: mitochondrial swelling, vacuolization, and cristae alteration have been described as common structural features of oocytes from AMA patients $(39,40)$. For instance, the mitochondrial membrane potential, which mirrors mitochondrial activity, is progressively altered (41). Similarly, a reduced ATP production and decreased metabolic activity in aged oocytes has been highlighted, which in turn may contribute to impairments in meiotic spindle assembly, cell cycle regulation, chromosome segregation, embryo development, and finally implantation $(40,42)$.

Mitochondrial-DNA lacks protective histones and efficient DNA repair mechanisms. Therefore, mtDNA mutation rate is about 25-times higher than nuclear-DNA one (43). Clearly, the longer the quiescent period, the higher the risk for mtDNA errors. Furthermore, also the overall concentration of mtDNA seems to be decreased in the oocytes from older patients $(44,45)$, thereby concurring to a lower oocyte/embryo competence (46-48). Of note, in humans, mitochondrial biogenesis is physiologically activated only at the blastocyst stage $(40,49)$ to limit the oxidative phosphorylation-induced stress in the first phases of embryo development. In older patients, the reduced amount and/or faulty activity of the pre-existing mitochondria within the oocyte may induce a compensatory premature initiation of mitochondrial biogenesis (50), which in turn may contribute to early embryo developmental failure (48).

Recently, mtDNA content in trophectoderm biopsies at the blastocyst stage has been proposed as a putative biomarker of implantation potential. However, the clinical studies conducted to date reported controversial results $(48,51-54)$. Indeed, lately, Humaidan and colleagues warned that it is still difficult to discriminate between "fact and fiction" in the current scenario and mtDNA cannot be considered a new biomarker of embryonic implantation potential (55): extensive validation, as well as more pre-clinical and possibly non-selection data, are yet required. Until then, the quantification of mtDNA from trophectoderm biopsies should be considered still an experimental procedure.

The mitochondria are also present in the granulosa cells (GCs) surrounding the oocyte already in the early phases of oogenesis. GCs are directly involved in establishing oocyte competence during oogenesis thanks to the well-known bi-directional dialog between these two sections of the follicle $(56,57)$. As for the oocytes, also GCs from AMA women showed higher levels of mtDNA deletions (58) and damaged mitochondria (59). The amount of mtDNA in GCs has been also reported to correlate with embryo quality (60) and poor ovarian reserve. The current hypothesis is that as the mtDNA in the oocyte supports the early embryonic development, similarly the mtDNA on its related GCs supports oocyte maturation, both possibly modulating embryo competence. Such hypothesis is supported by the high correlation between the mtDNA levels in the two compartments of the follicle (61).

In summary, aging can compromise both mtDNA integrity and/or mitochondria morphology or alter the microenvironment within the follicle and perturbate the mutual crosstalk between the oocyte and its GCs $(39,40,62)$.

\section{Shortening of the Telomeres}

The telomeres are short tandem repeats of specialized-DNA sequences that protect chromosome ends (63). Their function is essential for meiosis since, during the early prophase, the telomeres tether the chromosomes to the nuclear membrane to facilitate homologous pairing and initiate synapsis to form chiasmata, the physical sites of recombination responsible for normal segregation, thereby preventing non-disjunction $(64,65)$. Age-related telomeres shortening occurs either in dividing or non-dividing cells and has been associated with several age-related diseases (e.g., diabetes, cardiovascular diseases, and cancer) $(66,67)$. However, telomere dynamics extensively differ according to the cell type and gender. For instance, in the male germline, the length of the telomeres is preserved with aging, probably due to a constant activity of the telomerase (the reverse transcriptase involved in telomeres extension), which is expressed at high levels in the spermatogonia (68). Interestingly, an even increased mean length of the telomeres, as well as a higher length heterogeneity, has been recently reported in aged men with respect to younger patients (69). Conversely, the telomeres in the oocytes begin shortening during fetal oogenesis, and this process is continued in the adult ovary, probably due to the chronic effects of oxidative and genotoxic stress, the late exit of the female gametes from their cell cycle arrest, as well as to a reduced activity of the telomerase $(68,70,71)$. Furthermore, it has been demonstrated that the telomeres are shorter in oocytes from women who experienced IVF failure or recurrent miscarriage (72), as well as in oocytes resulting in fragmented (73) or aneuploid embryos (74). To this regard, Keefe and colleagues postulated the evolutionistic "telomeremediated oocyte aging" theory: preventing AMA women from conceiving would, in turn, prevent them from dying because of childbirth, thereby affecting the reproductive fitness of their offspring $(70,75)$.

\section{Cohesin Dysfunctions}

Loss of cohesion between sister chromatids close to the centromeres is another age-related dysfunction which may cause chromosomal missegregation. Cohesins are a complex of proteins that holds sister chromatids together after DNA replication and is responsible for maintaining the bivalent structure throughout the extended period of quiescence. Only at anaphase, the cohesins are removed to trigger the separation of sister chromatids. Gathering evidence is outlining an age-related disruption of cohesin function leading to missegregation within the oocyte, especially in the presence of low recombination rate (76). For instance, cytogenetic studies of human oocytes and embryos showed that PSSC is often associated with the age-related reduction of cohesins (e.g., Rec8, SA3, and SMC1b) $(77,78)$. Furthermore, also the activity of the regulatory proteins preventing a precocious removal of the cohesins seems to decline in an age-related fashion (79), regardless their nuclear location, which theoretically should protect them from the insults of mechanical stress and/or reactive-oxygen-species. Finally, a structural and functional interaction exists between cohesins and telomeres in mice (80). Therefore, in AMA patients, the age-related issues 
that affect the telomeres may trigger similar dysfunctions in the cohesins' activity (76).

\section{Spindle Instability}

The meiotic spindle is responsible for the separation of both homologous chromosomes and sister chromatids, therefore essential to ensure an accurate segregation (81). Aberrations in its assembly seem to contribute to the higher prevalence of aneuploidies in older women (82). These aberrations may also be ascribed to a decreased metabolic activity of mitochondria, resulting into a reduced amount of ATP because of AMA. The spindle of young oocytes is compact, orthogonally oriented with respect to the oolemma and each pole is associated with a ring of centrosome proteins. Conversely, nearly $80 \%$ of the oocytes in AMA patients may exhibit abnormal spindles with an elongated and/or smaller profile and few microtubular foci at the cortex $(81,82)$. To this regard, also the SAC, a ubiquitous safety protein complex that ensures a correct spindle formation (83), shows a reduced stringency with AMA (84-86). Different protein components of SAC (e.g., Mad2 and Bub1) showed indeed lower concentrations in oocytes from older women $(84,87)$.

\section{Other Putative Mechanisms Impaired by Aging}

Gene expression studies in oocytes from several species indicate that the activity of gene products involved in cell cycle regulation, spindle formation, and organelle integrity may be altered in oocytes from older individuals. For instance, in both murine and human oocytes $\sim 5 \%$ of all the transcripts detected at the MII stage were found to be affected by aging $(88,89)$. Possibly, the divergent signatures derive from the altered patterns of epigenetic modifications (e.g., methylation and acetylation), which have been indeed reported in both species (90-94). This field of reproductive genetics requires extensive investigations in the next years to better unveil these mechanisms.

\section{CLINICAL CONSIDERATIONS}

A clear correlation exists between increasing maternal age and decreasing success in conceiving both spontaneously and after $\operatorname{IVF}(4,5)$. Both reduced ovarian reserve and oocyte quality contribute to this scenario. Currently, no therapy exists to counteract infertility in AMA patients and we can only try to limit this biological and social issue.

First, fertility preservation via oocyte cryopreservation (95, 96) provides a valuable option to all women (not only oncological patients) aiming to prevent the natural decline of oocyte competence. Yet, the age at which fertility preservation is performed is an important effector of the ultimate outcome ( $<35$ years is preferable), and obviously the pregnancy cannot be guaranteed by oocyte banking (97).

Second, the maximization of ovarian reserve exploitation through tailored controlled-ovarian-stimulation (COS) is crucial to increase the number of oocytes collected, thereby also increasing the chance of success after IVF $(98,99)$. A higher number of oocytes collected per ovarian cycle might indeed compensate for the decrease in both oocyte quantity (i.e., ovarian reserve) and quality (i.e., competence). Therefore, novel COS strategies, such as oocyte/embryo accumulation in consecutive cycles (100) or double ovarian stimulation in the same ovarian cycle [i.e., the Shanghai (101) or the DuoStim protocol (102)], have been recently proposed to shorten the time invested by poor prognosis patients in their pursuit of a live birth. Promising data have been reported to this regard, especially in terms of cost-effectiveness and safety.

Third, the enhancement of embryo selection via preimplantation-genetic-testing represents another important option in AMA patients. In fact, the goal of ART is to achieve the birth of a healthy child minimizing the risks for the patient, and this is particularly true in AMA when the incidence of aneuploidies dramatically increases (10). This approach, by avoiding the transfer of aneuploid blastocysts and their related risks (i.e., implantation failures, miscarriages, and affected child), might result in an increased efficiency of each IVF treatment $(103,104)$. Importantly, once an euploid blastocyst is identified, its implantation potential is independent of maternal age (45-50\%), thereby allowing the adoption of a single-embryo-transfer policy also in AMA patients, concurrently lowering the risk for multiple gestations and their related obstetrical/perinatal risks $(105,106)$. Soon, the implementation of -omic sciences and the pursuit of non-invasiveness and higher cost-effectiveness in this field may converge and bring about intriguing avant-gardes to further improve embryo selection.

Finally, oocyte donation represents an effective approach to circumvent the age-related fertility decline. Recently, the optimization of cryopreservation techniques and the constitution of oocyte-banking facilities and programs allowed us to avoid synchronization between donors and recipients. Indeed, similar success rates derive from either fresh or frozen oocytes (107). Yet, in some countries oocyte donation is still forbidden and ethical/ psychological concerns limit its large-scale adoption.

\section{CONCLUSION}

Currently in IVF, a panel of experts focused on the management of poor prognosis patients, known as the POSEIDON group (Patient-Oriented Strategies Encompassing IndividualizeD Oocyte Number), has redefined the aim of ovarian stimulation (108). Specifically, they claimed that COS should be tailored "to retrieve the number of oocytes needed for the specific patient to obtain at least one euploid embryo for transfer." Such statement is based on two important assumptions: (i) aneuploidy rate in human blastocysts increases from a $30 \%$ baseline in women younger than 35 to $>90 \%$ in women older than $44(10,11)$ and (ii) the number of eggs collected and embryos obtained during IVF does not alter this rate (109). In other terms, the definition of the number of oocytes required (quantity) from each patient should entail the estimate of their competence (quality) aiming at obtaining at least one euploid blastocyst. Then, when performed, a euploid blastocyst transfer results into a healthy live birth in $\sim 50 \%$ of cases, regardless woman age (103).

To conclude, evidence-based data should always guide the counseling and the patients should be scrupulously informed about their estimated chance to conceive, especially if older than 35 . 
Indeed, 35 years should be the lowest age-threshold to define AMA and 45 years should be considered the highest age-threshold to undergo IVF with own eggs, at least according to the latest published report (9).

\section{REFERENCES}

1. Mills M, Rindfuss RR, McDonald P, te Velde E; ESHRE Reproduction and Society Task Force. Why do people postpone parenthood? Reasons and social policy incentives. Hum Reprod Update (2011) 17:848-60. doi:10.1093/ humupd/dmr026

2. Schmidt L, Sobotka T, Bentzen JG, Nyboe Andersen A; ESHRE Reproduction and Society Task Force. Demographic and medical consequences of the postponement of parenthood. Hum Reprod Update (2012) 18:29-43. doi:10.1093/humupd/dmr040

3. ESHRE Capri Workshop Group. Genetic aspects of female reproduction. Hum Reprod Update (2008) 14:293-307. doi:10.1093/humupd/dmn009

4. Heffner LJ. Advanced maternal age - how old is too old? N Engl J Med (2004) 351:1927-9. doi:10.1056/NEJMp048087

5. Nelson SM, Lawlor DA. Predicting live birth, preterm delivery, and low birth weight in infants born from in vitro fertilisation: a prospective study of 144,018 treatment cycles. PLoS Med (2011) 8:e1000386. doi:10.1371/ journal.pmed.1000386

6. Grondahl ML, Christiansen SL, Kesmodel US I, Agerholm E, Lemmen JG, Lundstrom P, et al. Effect of women's age on embryo morphology, cleavage rate and competence - a multicenter cohort study. PLoS One (2017) 12: e0172456. doi:10.1371/journal.pone.0172456

7. Stensen MH, Tanbo T, Storeng R, Byholm T, Fedorcsak P. Routine morphological scoring systems in assisted reproduction treatment fail to reflect age-related impairment of oocyte and embryo quality. Reprod Biomed Online (2010) 21:118-25. doi:10.1016/j.rbmo.2010.03.018

8. Mazzilli R, Cimadomo D, Vaiarelli A, Capalbo A, Dovere L, Alviggi E, et al. Effect of the male factor on the clinical outcome of intracytoplasmic sperm injection combined with preimplantation aneuploidy testing: observational longitudinal cohort study of 1,219 consecutive cycles. Fertil Steril (2017) 108(6):961-72.e3. doi:10.1016/j.fertnstert.2017.08.033

9. Ubaldi FM, Cimadomo D, Capalbo A, Vaiarelli A, Buffo L, Trabucco E, et al. Preimplantation genetic diagnosis for aneuploidy testing in women older than 44 years: a multicenter experience. Fertil Steril (2017) 107:1173-80. doi:10.1016/j.fertnstert.2017.03.007

10. Franasiak JM, Forman EJ, Hong KH, Werner MD, Upham KM, Treff NR, et al. The nature of aneuploidy with increasing age of the female partner: a review of 15,169 consecutive trophectoderm biopsies evaluated with comprehensive chromosomal screening. Fertil Steril (2014) 101:656-63.e1. doi:10.1016/j.fertnstert.2013.11.004

11. Capalbo A, Hoffmann ER, Cimadomo D, Maria Ubaldi F, Rienzi L. Human female meiosis revised: new insights into the mechanisms of chromosome segregation and aneuploidies from advanced genomics and time-lapse imaging. Hum Reprod Update (2017) 23(6):706-22. doi:10.1093/humupd/ dmx026

12. Santonocito M, Guglielmino MR, Vento M, Ragusa M, Barbagallo D, Borzi P, et al. The apoptotic transcriptome of the human MII oocyte: characterization and age-related changes. Apoptosis (2013) 18:201-11. doi:10.1007/ s10495-012-0783-5

13. Hassold T, Hunt P. To err (meiotically) is human: the genesis of human aneuploidy. Nat Rev Genet (2001) 2:280-91. doi:10.1038/35066065

14. Braude P, Bolton V, Moore S. Human gene expression first occurs between the four- and eight-cell stages of preimplantation development. Nature (1988) 332:459-61. doi:10.1038/332459a0

15. Nagaoka SI, Hassold TJ, Hunt PA. Human aneuploidy: mechanisms and new insights into an age-old problem. Nat Rev Genet (2012) 13:493-504. doi:10.1038/nrg3245

16. European I. V. F. Monitoring Consortium for the European Society of Human Reproduction, Embryology, Calhaz-Jorge C, de Geyter C, Kupka MS, de Mouzon J, Erb K, et al. Assisted reproductive technology in Europe, 2012: results generated from European registers by ESHRE. Hum Reprod (2016) 31:1638-52. doi:10.1093/humrep/dew151

\section{AUTHOR CONTRIBUTIONS}

DC and GF drafted the manuscript. All authors contributed in the literature search and discussion of the published evidence.

17. Hassold T, Hall H, Hunt P. The origin of human aneuploidy: where we have been, where we are going. Hum Mol Genet (2007) 16 Spec No. 2:R203-8. doi: $10.1093 / \mathrm{hmg} / \mathrm{ddm} 243$

18. Capalbo A, Rienzi L, Ubaldi FM. Diagnosis and clinical management of duplications and deletions. Fertil Steril (2017) 107:12-8. doi:10.1016/j. fertnstert.2016.11.002

19. Capalbo A, Ubaldi FM, Rienzi L, Scott R, Treff N. Detecting mosaicism in trophectoderm biopsies: current challenges and future possibilities. Hum Reprod (2016) 32(3):492-8. doi:10.1093/humrep/dew250

20. Angell RR. Meiosis I in human oocytes. Cytogenet Cell Genet (1995) 69:266-72. doi:10.1159/000133977

21. Duncan FE, Hornick JE, Lampson MA, Schultz RM, Shea LD, Woodruff TK. Chromosome cohesion decreases in human eggs with advanced maternal age. Aging Cell (2012) 11:1121-4. doi:10.1111/j.1474-9726.2012.00866.x

22. Patel J, Tan SL, Hartshorne GM, McAinsh AD. Unique geometry of sister kinetochores in human oocytes during meiosis I may explain maternal age-associated increases in chromosomal abnormalities. Biol Open (2015) 5:178-84. doi:10.1242/bio.016394

23. Zielinska AP, Holubcova Z, Blayney M, Elder K, Schuh M. Sister kinetochore splitting and precocious disintegration of bivalents could explain the maternal age effect. Elife (2015) 4:e11389. doi:10.7554/eLife.11389

24. Lagirand-Cantaloube J, Ciabrini C, Charrasse S, Ferrieres A, Castro A, Anahory T, et al. Loss of centromere cohesion in aneuploid human oocytes correlates with decreased kinetochore localization of the sac proteins Bub1 and Bubr1. Sci Rep (2017) 7:44001. doi:10.1038/srep44001

25. Kong A, Barnard J, Gudbjartsson DF, Thorleifsson G, Jonsdottir G, Sigurdardottir S, et al. Recombination rate and reproductive success in humans. Nat Genet (2004) 36:1203-6. doi:10.1038/ng1445

26. Ottolini CS, Newnham LJ, Capalbo A, Natesan SA, Joshi HA, Cimadomo D, et al. Genome-wide maps of recombination and chromosome segregation in human oocytes and embryos show selection for maternal recombination rates. Nat Genet (2015) 47:727-35. doi:10.1038/ng.3306

27. Capalbo A, Bono S, Spizzichino L, Biricik A, Baldi M, Colamaria S, et al. Sequential comprehensive chromosome analysis on polar bodies, blastomeres and trophoblast: insights into female meiotic errors and chromosomal segregation in the preimplantation window of embryo development. Hum Reprod (2013) 28:509-18. doi:10.1093/humrep/des394

28. Handyside AH, Montag M, Magli MC, Repping S, Harper J, Schmutzler A, et al. Multiple meiotic errors caused by predivision of chromatids in women of advanced maternal age undergoing in vitro fertilisation. Eur J Hum Genet (2012) 20:742-7. doi:10.1038/ejhg.2011.272

29. Hou Y, Fan W, Yan L, Li R, Lian Y, Huang J, et al. Genome analyses of single human oocytes. Cell (2013) 155:1492-506. doi:10.1016/j.cell.2013.11.040

30. Ottolini CS, Capalbo A, Newnham L, Cimadomo D, Natesan SA, Hoffmann ER, et al. Generation of meiomaps of genome-wide recombination and chromosome segregation in human oocytes. Nat Protoc (2016) 11:1229-43. doi:10.1038/nprot.2016.075

31. Polani PE, Jagiello GM. Chiasmata, meiotic univalents, and age in relation to aneuploid imbalance in mice. Cytogenet Cell Genet (1976) 16:505-29. doi:10.1159/000130668

32. Pellestor F, Andreo B, Arnal F, Humeau C, Demaille J. Mechanisms of non-disjunction in human female meiosis: the co-existence of two modes of malsegregation evidenced by the karyotyping of 1397 in-vitro unfertilized oocytes. Hum Reprod (2002) 17:2134-45. doi:10.1093/humrep/17.8.2134

33. Miao YL, Kikuchi K, Sun QY, Schatten H. Oocyte aging: cellular and molecular changes, developmental potential and reversal possibility. Hum Reprod Update (2009) 15:573-85. doi:10.1093/humupd/dmp014

34. Keefe D, Kumar M, Kalmbach K. Oocyte competency is the key to embryo potential. Fertil Steril (2015) 103:317-22. doi:10.1016/j.fertnstert.2014.12.115

35. Hutchison CA III, Newbold JE, Potter SS, Edgell MH. Maternal inheritance of mammalian mitochondrial DNA. Nature (1974) 251:536-8. doi: $10.1038 / 251536 \mathrm{a} 0$ 
36. Dumollard R, Duchen M, Carroll J. The role of mitochondrial function in the oocyte and embryo. Curr Top Dev Biol (2007) 77:21-49. doi:10.1016/ S0070-2153(06)77002-8

37. Van Blerkom J. Mitochondria in human oogenesis and preimplantation embryogenesis: engines of metabolism, ionic regulation and developmental competence. Reproduction (2004) 128:269-80. doi:10.1530/rep.1.00240

38. Dumollard R, Ward Z, Carroll J, Duchen MR. Regulation of redox metabolism in the mouse oocyte and embryo. Development (2007) 134:455-65. doi:10.1242/dev.02744

39. Muller-Hocker J, Schafer S, Weis S, Munscher C, Strowitzki T. Morphologicalcytochemical and molecular genetic analyses of mitochondria in isolated human oocytes in the reproductive age. Mol Hum Reprod (1996) 2:951-8. doi:10.1093/molehr/2.12.951

40. Van Blerkom J. Mitochondrial function in the human oocyte and embryo and their role in developmental competence. Mitochondrion (2011) 11: 797-813. doi:10.1016/j.mito.2010.09.012

41. Wilding M, Dale B, Marino M, di Matteo L, Alviggi C, Pisaturo ML, et al. Mitochondrial aggregation patterns and activity in human oocytes and preimplantation embryos. Hum Reprod (2001) 16:909-17. doi:10.1093/ humrep/16.5.909

42. Eichenlaub-Ritter U. Oocyte ageing and its cellular basis. Int J Dev Biol (2012) 56:841-52. doi:10.1387/ijdb.120141ue

43. Lynch M, Koskella B, Schaack S. Mutation pressure and the evolution of organelle genomic architecture. Science (2006) 311:1727-30. doi:10.1126/ science. 1118884

44. Duran HE, Simsek-Duran F, Oehninger SC, Jones HW Jr, Castora FJ. The association of reproductive senescence with mitochondrial quantity, function, and DNA integrity in human oocytes at different stages of maturation. Fertil Steril (2011) 96:384-8. doi:10.1016/j.fertnstert.2011.05.056

45. Murakoshi Y, Sueoka K, Takahashi K, Sato S, Sakurai T, Tajima H, et al. Embryo developmental capability and pregnancy outcome are related to the mitochondrial DNA copy number and ooplasmic volume. J Assist Reprod Genet (2013) 30:1367-75. doi:10.1007/s10815-013-0062-6

46. Reynier P, May-Panloup P, Chretien MF, Morgan CJ, Jean M, Savagner F, et al. Mitochondrial DNA content affects the fertilizability of human oocytes. Mol Hum Reprod (2001) 7:425-9. doi:10.1093/molehr/7.5.425

47. Santos TA, El Shourbagy S, St John JC. Mitochondrial content reflects oocyte variability and fertilization outcome. Fertil Steril (2006) 85:584-91. doi:10.1016/j.fertnstert.2005.09.017

48. Diez-Juan A, Rubio C, Marin C, Martinez S, Al-Asmar N, Riboldi M, et al. Mitochondrial DNA content as a viability score in human euploid embryos: less is better. Fertil Steril (2015) 104:534-41.e1. doi:10.1016/j. fertnstert.2015.05.022

49. Sathananthan AH, Trounson AO. Mitochondrial morphology during preimplantational human embryogenesis. Hum Reprod (2000) 15(Suppl 2): 148-59. doi:10.1093/humrep/15.suppl_2.148

50. May-Panloup P, Boucret L, Chao de la Barca JM, Desquiret-Dumas V, FerreL'Hotellier V, Moriniere C, et al. Ovarian ageing: the role of mitochondria in oocytes and follicles. Hum Reprod Update (2016) 22:725-43. doi:10.1093/ humupd/dmw028

51. Treff NR, Zhan Y, Tao X, Olcha M, Han M, Rajchel J, et al. Levels of trophectoderm mitochondrial DNA do not predict the reproductive potential of sibling embryos. Hum Reprod (2017) 32:954-62. doi:10.1093/humrep/ dex034

52. Fragouli E, McCaffrey C, Ravichandran K, Spath K, Grifo JA, Munne S, et al. Clinical implications of mitochondrial DNA quantification on pregnancy outcomes: a blinded prospective non-selection study. Hum Reprod (2017) 32:2340-7. doi:10.1093/humrep/dex292

53. Victor AR, Brake AJ, Tyndall JC, Griffin DK, Zouves CG, Barnes FL, et al. Accurate quantitation of mitochondrial DNA reveals uniform levels in human blastocysts irrespective of ploidy, age, or implantation potential. Fertil Steril (2017) 107:34-42.e3. doi:10.1016/j.fertnstert.2016.09.028

54. de Los Santos MJ, Diez Juan A, Mifsud A, Mercader A, Meseguer M, Rubio C, et al. Variables associated with mitochondrial copy number in human blastocysts: what can we learn from trophectoderm biopsies? Fertil Steril (2018) 109:110-7. doi:10.1016/j.fertnstert.2017.09.022

55. Humaidan P, Kristensen SG, Coetzee K. Mitochondrial DNA, a new biomarker of embryonic implantation potential: fact or fiction? Fertil Steril (2018) 109:61-2. doi:10.1016/j.fertnstert.2017.10.017
56. Buccione R, Schroeder AC, Eppig JJ. Interactions between somatic cells and germ cells throughout mammalian oogenesis. Biol Reprod (1990) 43:543-7. doi:10.1095/biolreprod43.4.543

57. Gilchrist RB, Lane M, Thompson JG. Oocyte-secreted factors: regulators of cumulus cell function and oocyte quality. Hum Reprod Update (2008) 14:159-77. doi:10.1093/humupd/dmm040

58. Seifer DB, DeJesus V, Hubbard K. Mitochondrial deletions in luteinized granulosa cells as a function of age in women undergoing in vitro fertilization. Fertil Steril (2002) 78:1046-8. doi:10.1016/S0015-0282(02)04214-0

59. Tatone C, Carbone MC, Falone S, Aimola P, Giardinelli A, Caserta D, et al. Age-dependent changes in the expression of superoxide dismutases and catalase are associated with ultrastructural modifications in human granulosa cells. Mol Hum Reprod (2006) 12:655-60. doi:10.1093/molehr/gal080

60. Ogino M, Tsubamoto H, Sakata K, Oohama N, Hayakawa H, Kojima T, et al. Mitochondrial DNA copy number in cumulus cells is a strong predictor of obtaining good-quality embryos after IVF. J Assist Reprod Genet (2016) 33:367-71. doi:10.1007/s10815-015-0621-0

61. Boucret L, Chao de la Barca JM, Moriniere C, Desquiret V, Ferre-LHotellier $\mathrm{V}$, Descamps $\mathrm{P}$, et al. Relationship between diminished ovarian reserve and mitochondrial biogenesis in cumulus cells. Hum Reprod (2015) 30:1653-64. doi:10.1093/humrep/dev114

62. Tatone C, Amicarelli F, Carbone MC, Monteleone P, Caserta D, Marci R, et al. Cellular and molecular aspects of ovarian follicle ageing. Hum Reprod Update (2008) 14:131-42. doi:10.1093/humupd/dmm048

63. de Lange T. How telomeres solve the end-protection problem. Science (2009) 326:948-52. doi:10.1126/science.1170633

64. Bass HW, Riera-Lizarazu O, Ananiev EV, Bordoli SJ, Rines HW, Phillips RL, et al. Evidence for the coincident initiation of homolog pairing and synapsis during the telomere-clustering (bouquet) stage of meiotic prophase. J Cell Sci (2000) 113(Pt 6):1033-42.

65. Scherthan H. Telomere attachment and clustering during meiosis. Cell Mol Life Sci (2007) 64:117-24. doi:10.1007/s00018-006-6463-2

66. Martinez-Delgado B, Yanowsky K, Inglada-Perez L, Domingo S, Urioste M, Osorio A, et al. Genetic anticipation is associated with telomere shortening in hereditary breast cancer. PLoS Genet (2011) 7:e1002182. doi:10.1371/ journal.pgen.1002182

67. Calado RT, Young NS. Telomere diseases. N Engl J Med (2009) 361:2353-65. doi:10.1056/NEJMra0903373

68. Kalmbach KH, Fontes Antunes DM, Dracxler RC, Knier TW, SethSmith ML, Wang F, et al. Telomeres and human reproduction. Fertil Steril (2013) 99:23-9. doi:10.1016/j.fertnstert.2012.11.039

69. Antunes DM, Kalmbach KH, Wang F, Dracxler RC, Seth-Smith ML, Kramer Y, et al. A single-cell assay for telomere DNA content shows increasing telomere length heterogeneity, as well as increasing mean telomere length in human spermatozoa with advancing age. J Assist Reprod Genet (2015) 32:1685-90. doi:10.1007/s10815-015-0574-3

70. Keefe DL, Marquard K, Liu L. The telomere theory of reproductive senescence in women. Curr Opin Obstet Gynecol (2006) 18:280-5. doi:10.1097/01. gco.0000193019.05686.49

71. Keefe DL. Telomeres, reproductive aging, and genomic instability during early development. Reprod Sci (2016) 23:1612-5. doi:10.1177/ 1933719116676397

72. Mania A, Mantzouratou A, Delhanty JD, Baio G, Serhal P, Sengupta SB. Telomere length in human blastocysts. Reprod Biomed Online (2014) 28:624-37. doi:10.1016/j.rbmo.2013.12.010

73. Keefe DL, Franco S, Liu L, Trimarchi J, Cao B, Weitzen S, et al. Telomere length predicts embryo fragmentation after in vitro fertilization in women - toward a telomere theory of reproductive aging in women. Am J Obstet Gynecol (2005) 192:1256-60; discussion 60-1. doi:10.1016/j.ajog.2005.01.036

74. Treff NR, Su J, Taylor D, Scott RT Jr. Telomere DNA deficiency is associated with development of human embryonic aneuploidy. PLoS Genet (2011) 7:e1002161. doi:10.1371/journal.pgen.1002161

75. Keefe DL, Liu L. Telomeres and reproductive aging. Reprod Fertil Dev (2009) 21:10-4. doi:10.1071/RD08229

76. Cheng JM, Liu YX. Age-related loss of cohesion: causes and effects. Int J Mol Sci (2017) 18. doi:10.3390/ijms18071578

77. Xu H, Beasley MD, Warren WD, van der Horst GT, McKay MJ. Absence of mouse REC8 cohesin promotes synapsis of sister chromatids in meiosis. Dev Cell (2005) 8:949-61. doi:10.1016/j.devcel.2005.03.018 
78. Tsutsumi M, Fujiwara R, Nishizawa H, Ito M, Kogo H, Inagaki H, et al. Age-related decrease of meiotic cohesins in human oocytes. PLoS One (2014) 9:e96710. doi:10.1371/journal.pone.0096710

79. Lister LM, Kouznetsova A, Hyslop LA, Kalleas D, Pace SL, Barel JC, et al. Age-related meiotic segregation errors in mammalian oocytes are preceded by depletion of cohesin and Sgo2. Curr Biol (2010) 20:1511-21. doi:10.1016/ j.cub.2010.08.023

80. Remeseiro S, Cuadrado A, Carretero M, Martinez P, Drosopoulos WC, Canamero M, et al. Cohesin-SA1 deficiency drives aneuploidy and tumourigenesis in mice due to impaired replication of telomeres. EMBO J (2012) 31:2076-89. doi:10.1038/emboj.2012.11

81. Bennabi I, Terret ME, Verlhac MH. Meiotic spindle assembly and chromosome segregation in oocytes. J Cell Biol (2016) 215:611-9. doi:10.1083/ jcb.201607062

82. Battaglia DE, Goodwin P, Klein NA, Soules MR. Influence of maternal age on meiotic spindle assembly in oocytes from naturally cycling women. Hum Reprod (1996) 11:2217-22. doi:10.1093/oxfordjournals.humrep. a019080

83. Brunet S, Pahlavan G, Taylor S, Maro B. Functionality of the spindle checkpoint during the first meiotic division of mammalian oocytes. Reproduction (2003) 126:443-50. doi:10.1530/rep.0.1260443

84. Steuerwald N, Cohen J, Herrera RJ, Sandalinas M, Brenner CA. Association between spindle assembly checkpoint expression and maternal age in human oocytes. Mol Hum Reprod (2001) 7:49-55. doi:10.1093/molehr/7.1.49

85. Kolano A, Brunet S, Silk AD, Cleveland DW, Verlhac MH. Error-prone mammalian female meiosis from silencing the spindle assembly checkpoint without normal interkinetochore tension. Proc Natl Acad Sci U S A (2012) 109:E1858-67. doi:10.1073/pnas.1204686109

86. Nagaoka SI, Hodges CA, Albertini DF, Hunt PA. Oocyte-specific differences in cell-cycle control create an innate susceptibility to meiotic errors. Curr Biol (2011) 21:651-7. doi:10.1016/j.cub.2011.03.003

87. Steuerwald NM, Bermudez MG, Wells D, Munne S, Cohen J. Maternal age-related differential global expression profiles observed in human oocytes. Reprod Biomed Online (2007) 14:700-8. doi:10.1016/S1472-6483 (10)60671-2

88. Hamatani T, Falco G, Carter MG, Akutsu H, Stagg CA, Sharov AA, et al. Age-associated alteration of gene expression patterns in mouse oocytes. Hum Mol Genet (2004) 13:2263-78. doi:10.1093/hmg/ddh241

89. Grondahl ML, Yding Andersen C, Bogstad J, Nielsen FC, Meinertz H, Borup R. Gene expression profiles of single human mature oocytes in relation to age. Hum Reprod (2010) 25:957-68. doi:10.1093/humrep/deq014

90. Ge ZJ, Schatten H, Zhang CL, Sun QY. Oocyte ageing and epigenetics. Reproduction (2015) 149:R103-14. doi:10.1530/REP-14-0242

91. van den Berg IM, Eleveld C, van der Hoeven M, Birnie E, Steegers EA, Galjaard RJ, et al. Defective deacetylation of histone $4 \mathrm{~K} 12$ in human oocytes is associated with advanced maternal age and chromosome misalignment. Hum Reprod (2011) 26:1181-90. doi:10.1093/humrep/der030

92. Ratnam S, Mertineit C, Ding F, Howell CY, Clarke HJ, Bestor TH, et al. Dynamics of Dnmtl methyltransferase expression and intracellular localization during oogenesis and preimplantation development. Dev Biol (2002) 245:304-14. doi:10.1006/dbio.2002.0628

93. Mohan KN, Ding F, Chaillet JR. Distinct roles of DMAP1 in mouse development. Mol Cell Biol (2011) 31:1861-9. doi:10.1128/MCB.01390-10

94. Zhang L, Lu DY, Ma WY, Li Y. Age-related changes in the localization of DNA methyltransferases during meiotic maturation in mouse oocytes. Fertil Steril (2011) 95:1531-4.e1. doi:10.1016/j.fertnstert.2010.06.050

95. ESHRE Task Force on Ethics and Law, Dondorp W, de Wert G, Pennings G, Shenfield F, Devroey P, et al. Oocyte cryopreservation for age-related fertility loss. Hum Reprod (2012) 27:1231-7. doi:10.1093/humrep/des029

96. Stoop D, van der Veen F, Deneyer M, Nekkebroeck J, Tournaye H. Oocyte banking for anticipated gamete exhaustion (AGE) is a preventive intervention, neither social nor nonmedical. Reprod Biomed Online (2014) 28:548-51. doi:10.1016/j.rbmo.2014.01.007
97. Cil AP, Bang H, Oktay K. Age-specific probability of live birth with oocyte cryopreservation: an individual patient data meta-analysis. Fertil Steril (2013) 100:492-9.e3. doi:10.1016/j.fertnstert.2013.04.023

98. Steward RG, Lan L, Shah AA, Yeh JS, Price TM, Goldfarb JM, et al. Oocyte number as a predictor for ovarian hyperstimulation syndrome and live birth: an analysis of 256,381 in vitro fertilization cycles. Fertil Steril (2014) 101:967-73. doi:10.1016/j.fertnstert.2013.12.026

99. Drakopoulos P, Blockeel C, Stoop D, Camus M, de Vos M, Tournaye H, et al. Conventional ovarian stimulation and single embryo transfer for IVF/ICSI. How many oocytes do we need to maximize cumulative live birth rates after utilization of all fresh and frozen embryos? Hum Reprod (2016) 31:370-6. doi:10.1093/humrep/dev316

100. Cobo A, Garrido N, Crespo J, Jose R, Pellicer A. Accumulation of oocytes: a new strategy for managing low-responder patients. Reprod Biomed Online (2012) 24:424-32. doi:10.1016/j.rbmo.2011.12.012

101. Kuang Y, Chen Q, Hong Q, Lyu Q, Ai A, Fu Y, et al. Double stimulations during the follicular and luteal phases of poor responders in IVF/ICSI programmes (Shanghai protocol). Reprod Biomed Online (2014) 29:684-91. doi:10.1016/j.rbmo.2014.08.009

102. Ubaldi FM, Capalbo A, Vaiarelli A, Cimadomo D, Colamaria S, Alviggi C, et al. Follicular versus luteal phase ovarian stimulation during the same menstrual cycle (DuoStim) in a reduced ovarian reserve population results in a similar euploid blastocyst formation rate: new insight in ovarian reserve exploitation. Fertil Steril (2016) 105:1488-95.e1. doi:10.1016/j. fertnstert.2016.03.002

103. Dahdouh EM, Balayla J, Garcia-Velasco JA. Comprehensive chromosome screening improves embryo selection: a meta-analysis. Fertil Steril (2015) 104:1503-12. doi:10.1016/j.fertnstert.2015.08.038

104. Chen M, Wei S, Hu J, Quan S. Can comprehensive chromosome screening technology improve IVF/ICSI outcomes? A meta-analysis. PLoS One (2015) 10:e0140779. doi:10.1371/journal.pone.0140779

105. Forman EJ, Hong KH, Ferry KM, Tao X, Taylor D, Levy B, et al. In vitro fertilization with single euploid blastocyst transfer: a randomized controlled trial. Fertil Steril (2013) 100:100-7.e1. doi:10.1016/j.fertnstert.2013.02.056

106. Forman EJ, Hong KH, Franasiak JM, Scott RT Jr. Obstetrical and neonatal outcomes from the BEST Trial: single embryo transfer with aneuploidy screening improves outcomes after in vitro fertilization without compromising delivery rates. Am J Obstet Gynecol (2014) 210:157.e1-6. doi:10.1016/j. ajog.2013.10.016

107. Practice Committees of American Society for Reproductive Medicine and the Society for Assisted Reproductive Technology. Mature oocyte cryopreservation: a guideline. Fertil Steril (2013) 99:37-43. doi:10.1016/ j.fertnstert.2012.09.028

108. Poseidon Group, Alviggi C, Andersen CY, Buehler K, Conforti A, De Placido $G$, et al. A new more detailed stratification of low responders to ovarian stimulation: from a poor ovarian response to a low prognosis concept. Fertil Steril (2016) 105:1452-3. doi:10.1016/j.fertnstert.2016.02.005

109. Ata B, Kaplan B, Danzer H, Glassner M, Opsahl M, Tan SL, et al. Array $\mathrm{CGH}$ analysis shows that aneuploidy is not related to the number of embryos generated. Reprod Biomed Online (2012) 24:614-20. doi:10.1016/j. rbmo.2012.02.009

Conflict of Interest Statement: The authors declare that the research was conducted in the absence of any commercial or financial relationships that could be construed as a potential conflict of interest.

Copyright (c) 2018 Cimadomo, Fabozzi, Vaiarelli, Ubaldi, Ubaldi and Rienzi. This is an open-access article distributed under the terms of the Creative Commons Attribution License (CC BY). The use, distribution or reproduction in other forums is permitted, provided the original author(s) and the copyright owner are credited and that the original publication in this journal is cited, in accordance with accepted academic practice. No use, distribution or reproduction is permitted which does not comply with these terms. 